\title{
Absence of homozygosity for predominant mutations in PMM2 in Danish patients with carbohydrate-deficient glycoprotein syndrome type 1
}

\author{
Susanne K jaergaard, Flemming Skovby and M arianne Schwartz \\ D epartment of Clinical G enetics, The Juliane M arie Centre, U niversity H ospital, Rigshospitalet, Copenhagen, \\ D enmark
}

\begin{abstract}
Carbohydrate-deficient glycoprotein syndrome type 1 (CDG1; McKusick No. 212065) is an autosomal recessively inherited disease characterised clinically by central nervous system dysfunction and biochemically by hypoglycosylation of many serum proteins. Most patients with CDG1 have deficient activity of phosphomannomutase. The locus for this enzyme has been mapped to 16 13, and a gene, PMM2, encoding phosphomannomutase has been isolated. We identified 34 mutations on $\mathbf{3 6}$ disease chromosomes in 18 unrelated Danish patients with CDG1. All patients have less than $15 \%$ residual activity of phosphomannomutase. Two mutations account for $88 \%$ of all mutations: F119L and R141H were each found in 16 out of 36 CDG1 alleles. These two mutations were found to be in linkage disequilibrium with two different alleles of the marker D16S3020, suggesting that there is one ancestral origin for each mutation. Two new mutations, G117R and D223E, were identified also. Surprisingly, no patient was homozygous for either of the two common mutations, suggesting that homozygosity for these mutations is either lethal or so benign that such patients are not detected.
\end{abstract}

Keywords: CDG1; PMM2; mutation; phosphomannomutase; linkage disequilibrium

\section{Introduction}

Carbohydrate-deficient glycoprotein syndrome type 1 (CDG 1) is an autosomal recessively inherited disorder with multisystemic abnormalities including psychomo-

Correspondence: Marianne Schwartz PhD, Department of Clinical G enetics, U niversity Hospital, R igshospitalet 4062, B legdamsvej 9, DK -2100 Copenhagen, D enmark. Tel: ( +45) $35 \quad 45 \quad 48$ 65; Fax: $(+45) \quad 35 \quad 45 \quad 40 \quad 72$; $\quad$ E-mail: schwartz@rh.dk

Received 21 November 1997; revised 23 January 1998; accepted 30 J anuary 1998 tor retardation, hepatic dysfunction and dysmorphic features. ${ }^{1,2}$ Biochemical diagnosis relies on isoelectric focusing of serum glycoproteins which shows a cathodal shift of isoforms due to undersialylation. ${ }^{3}$ The majority of CDG 1 patients have a deficiency of phosphomannomutase which converts mannose-6-P to mannose$1-P^{4-6}$

A locus for CDG 1 has been mapped to $16 p 13,{ }^{7-9}$ and overrepresentation of a certain haplotype in CDG 1 families from southern Scandinavia suggests the presence of a specific mutation with a founder effect in this 
area. ${ }^{9}$ R ecently, two genes, both encoding a phosphomannomutase, have been cloned on the basis of their homology to yeast phosphomannomutase SE C 53. ${ }^{10-12}$ The first gene, PMM 1, is localised on chromosome $22 q 13$ and can therefore be excluded as a CDG 1 candidate gene. $^{10,11}$ The second gene, PM M 2, is located on 16p13, and a number of different mutations in PM M 2 have been identified in patients with CDG $1,{ }^{12}$ strongly suggesting that deficiency of the phosphomannomutase encoded by PM M 2 is responsible for the phenotype in these patients, although expression studies have not yet been published. F urthermore, the role of the phosphomannomutase encoded by PM M 1 is not clear. We now report our investigation of $18 \mathrm{D}$ anish CDG 1 patients, including the determination of their specific activity of phosphomannomutase, a comparison of their CDG 1 chromosome DNA haplotypes, and a search for their mutations in PM M 2.

\section{Materials and Methods}

\section{Patients}

Twenty-two patients and their parents from 18 unrelated families were included in this study. The clinical diagnosis of CDG 1 had previously been substantiated by isoelectric focusing of transferrin and determination of carbohydratedeficient transferrin in serum according to Stibler et al. ${ }^{3}$

\section{Phosphomannomutase Assay}

The specific activity of phosphomannomutase was determined in cultured fibroblasts by the method described by $V$ an Schaftingen and Jaeken. ${ }^{4}$

\section{Microsatellite Analysis}

A II family members were typed for the microsatellite markers GATA-P6084, A FM a284wd5, D 16S406 and D 16S3020. ${ }^{13}$ Primer sequences were obtained from $G$ enome Data Base. One primer in each set was 5'-labelled with FITC (fluorescein-isothiocyanate). The PCR products were analysed on an A.L.F. DNA sequencer using the Fragment $M$ anager software (Pharmacia B iotech, U ppsala, Sweden).

\section{Screening for Mutations by Single Strand Conformation Analysis (SSCA)}

PCR A II eight exons and flanking introns were amplified using the primers described by Matthijs et al. ${ }^{14}$

SSCA PCR products were denatured by mixing $3 \mu$ with an equal volume of loading mixture ( $95 \%$ formamide, $20 \mathrm{mM}$ EDTA , $0.05 \%$ bromophenol blue and $0.05 \%$ xylene cyanol), followed by boiling for $5 \mathrm{~min}$ and cooling on ice. Of each denatured sample $2 \mu \mathrm{l}$ were loaded on a $20 \%$ homogeneous PHAST-gel with native buffer strips (Pharmacia Biotech, U ppsala, Sweden). The separation conditions consisted of a prerun for 10 avh (average volt hours) at $5 \mathrm{~mA}, 1 \mathrm{~W}$, and $400 \mathrm{~V}$; a sample application for 2 avh at $5 \mathrm{~mA}, 1 \mathrm{~W}$, and $25 \mathrm{~V}$; and a separation for 310 avh at $5 \mathrm{~mA}, 2 \mathrm{~W}$, and $450 \mathrm{~V}$. Singlestrand products were visualised by silver staining according to the PHASTsystem recommendations. PCR products with altered electrophoretic mobility were reamplified and sequenced.

\section{Direct DNA Sequencing}

5 '-biotinylated reverse primers with sequences identical to those used for SSCA for the amplification of exons 5 and 8 were employed. The PCR products were purified using the QIA quick PCR purification kit (Qiagen, Düsseldorf, Germany). Single-strand DNA was isolated by the use of D ynabeads M -250 Streptavidin (D ynal, O slo, Norway) and a Dynal magnetic separator and subsequently sequenced with the Sequenase kit version 2.0 (U SB, Cleveland, O hio), using the forward primers in the PCR amplification as sequencing primers.

\section{Confirmation of Mutations by Restriction Analysis}

Simultaneous detection of F119L and R $141 \mathrm{H}$ : these mutations are located in exon 5 of PMM2. U sing the primers R $141 \mathrm{H}$ misR and intU 2 (Table 2) a PCR product of $250 \mathrm{bp}$ spanning both mutations was obtained. The primer $\mathrm{R} 141 \mathrm{H}$ misR introduces a restriction site for M lul in the PCR product of the normal allele, but not in that of the allele harbouring $\mathrm{R} 141 \mathrm{H}$. The mutation $\mathrm{F} 119 \mathrm{~L}$ creates a restriction site for M sel. A fter amplification two $10 \mu \mathrm{l}$ aliquots of the amplification mixture were incubated with the appropriate restriction enzyme/buffer in a total volume of $20 \mu \mathrm{l}$ and subsequently analysed by agarose gel electrophoresis.

The presence of $G 117 R$ was detected using the primers $\mathrm{G} 117 \mathrm{R}$ mis and 2BF. The primer G 117R mis will introduce $\mathrm{a}$ restriction site for $A$ val, except in the presence of G117R. D 223E introduces a restriction site for Bsp1286I, using the primers int7B B and 8R new (Figure 1).

\section{Results}

Cultured skin fibroblasts were available from 16 unrelated patients with CDG1. The specific activity of phosphomannomutase in extracts of these cells ranged
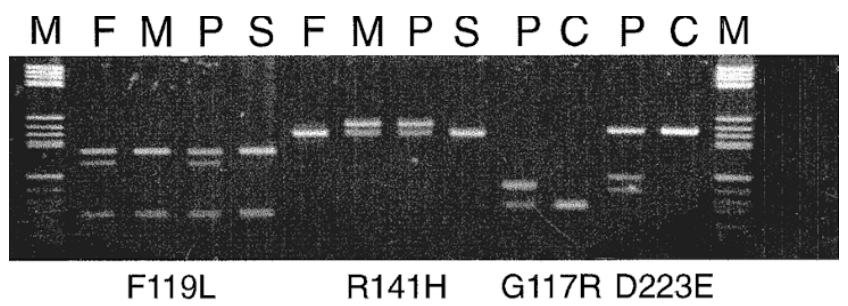

Figure 1 Restriction analyses for detection of the mutations F119L, R141H, G117R and D223E. M (molecular size markers). The next eight lanes show the restriction analyses of family 2. The patient $(P)$ is positive for both $F 119 L$ ( $M$ sel) and $\mathrm{R} 141 \mathrm{H}$ (M lul). The father (F) is heterozygous for $\mathrm{F} 119 \mathrm{~L}$, the mother $(M)$ is heterozygous for $\mathrm{R} 141 \mathrm{H}$, whereas a healthy sib (S) does not harbour any of the mutations. The next four lanes show the restriction analyses for patient $1 \mathrm{G} \mathrm{117R}$ (A val) and for patient 8 with the mutation D 223E (B sp1286I). 
Table 1 PM M activities and mutations identified in 18 CDG 1 patients of $D$ anish origin

\begin{tabular}{|c|c|c|c|c|c|}
\hline Fam nr. & $\begin{array}{l}\mathrm{nmol} / \mathrm{min} / \\
\mathrm{mg} \text { proteina }\end{array}$ & M utation 1 & $\begin{array}{l}\text { A mino acid } \\
\text { change }\end{array}$ & M utation 2 & $\begin{array}{l}\text { A mino acid } \\
\text { change }\end{array}$ \\
\hline 1 & $<0.2$ & $669 \mathrm{C} \rightarrow \mathrm{G}$ & D 223E & $?$ & $?$ \\
\hline 2 & 0.4 & $357 \mathrm{C} \rightarrow \mathrm{A}$ & F $119 L$ & $425 G \rightarrow A$ & R $141 \mathrm{H}$ \\
\hline 3 & 0.5 & $357 \mathrm{C} \rightarrow \mathrm{A}$ & F119L & $425 G \rightarrow A$ & R $141 \mathrm{H}$ \\
\hline 4 & $<0.2$ & $357 \mathrm{C} \rightarrow \mathrm{A}$ & F 119L & $425 G \rightarrow A$ & R 141H \\
\hline 5 & 0.3 & $357 C \rightarrow A$ & F 119L & $425 G \rightarrow A$ & R 141H \\
\hline 6 & $<0.2$ & $357 C \rightarrow A$ & F119L & $425 G \rightarrow A$ & R 141H \\
\hline 7 & 0.3 & $357 \mathrm{C} \rightarrow \mathrm{A}$ & F 119L & $425 G \rightarrow A$ & R $141 \mathrm{H}$ \\
\hline 8 & 0.4 & $357 \mathrm{C} \rightarrow \mathrm{A}$ & F 119L & $349 G \rightarrow C$ & G 117R \\
\hline 9 & $<0.2$ & ? & $?$ & $425 G \rightarrow A$ & R $141 \mathrm{H}$ \\
\hline 10 & 0.5 & $357 C \rightarrow A$ & F 119L & $425 G \rightarrow A$ & R 141H \\
\hline 11 & $<0.2$ & $357 C \rightarrow A$ & F119L & $425 G \rightarrow A$ & R $141 \mathrm{H}$ \\
\hline 12 & $<0.2$ & $357 C \rightarrow A$ & F 119L & $425 G \rightarrow A$ & R 141H \\
\hline 13 & $<0.2$ & $357 C \rightarrow A$ & F119L & $425 G \rightarrow A$ & R $141 \mathrm{H}$ \\
\hline 14 & $<0.2$ & $357 \mathrm{C} \rightarrow \mathrm{A}$ & F 119L & $425 G \rightarrow A$ & R 141H \\
\hline 15 & n.d. & $357 C \rightarrow A$ & F 119L & $425 G \rightarrow A$ & R 141H \\
\hline 16 & n.d. & $357 \mathrm{C} \rightarrow \mathrm{A}$ & F119L & $425 G \rightarrow A$ & R $141 \mathrm{H}$ \\
\hline 17 & $<0.2$ & $357 \mathrm{C} \rightarrow \mathrm{A}$ & F 119L & $425 G \rightarrow A$ & R $141 \mathrm{H}$ \\
\hline 18 & 0.4 & $357 C \rightarrow A$ & F 119L & $425 G \rightarrow A$ & R 141H \\
\hline
\end{tabular}

aControl: $3.1 \pm 1.0(n=9) . n \cdot d .=$ not determined.

from undetectable to $15 \%$ of normal activity (Table 1).

In order to identify the disease-causing mutations in PMM 2 all eight exons and flanking introns were initially screened by means of SSCA, using genomic DNA from 18 unrelated patients with CDG 1 . Exon 5 was analysed in two fragments, $5 A$ and $5 B$. Several different aberrant SSCA patterns of $5 A, 5 B$ and exon 8 were detected. Direct sequencing of reamplified $5 A$ and $5 B$ products revealed the mutations $357 C \rightarrow A$ (F119L) and 425G $\rightarrow A(R 141 \mathrm{H})$, respectively (Table 1$)$. $\mathrm{U}$ sing a primer pair flanking both mutations (Table 2), it was possible to verify the presence or absence of both of the above mutations by restriction analysis of a single PCR product. Compound heterozygosity for $\mathrm{R} 141 \mathrm{H}$ and F119L was found in 15 of the 18 patients, and their parents were heterozygous for the mutations in question.
Furthermore, we identified two novel missense mutations, 349G $\rightarrow C$ ( G 117R) in exon 5 of PM M 2 in patient 8 and $669 C \rightarrow G(D 223 E)$ in exon 8 in patient 1 . In addition to D223E we identified a $3 \mathrm{bp}$ deletion, 348-58delA TG, on the paternal chromosome of patient 1. No mutation was identified on this patient's maternal chromosome. The presence of G $117 R$ and D 223E was confirmed by restriction analysis of appropriate PCR products (Figure 1 ). No patient was homozygous for either of the common mutations.

It has previously been reported that a marker haplotype, A, defined by the microsatellites GATA P6084 (or D 16S768), A FMa284wd5, and D 165406 is markedly overrepresented on CDG 1 chromosomes in patients from southern Scandinavia. ${ }^{9}$ In order to determine which of the two common mutations was associated with this haplotype we determined the haplotypes in all available family members using the

Table 2 Primers used for confirmation of the mutations by restriction analysis

\begin{tabular}{llll}
\hline M utation & Name & & Ann temp $\left({ }^{\circ} \mathrm{C}\right)$ \\
\hline F $119 \mathrm{~L} /$ & intU 2 & GCACAGAGCTGAGAAACATT & 60 \\
R $141 \mathrm{H}$ & R $141 \mathrm{H}$ misRa & GTACTTTATCGAGTTCGTAGAACTCAACG & \\
& 2BF & TGCGTTCTTCTTGGCTGCAGC & 55 \\
G $117 \mathrm{R}$ & G $117 \mathrm{R}$ misa & AGAACTCTGTCACCCTTTCATTCCCCGG & \\
D $223 \mathrm{E}$ & int7FB & TCCAGGGTCACATCAGCAATGG & 52 \\
& 8R new & CCTATGCCTGCTTGTCAGCCG & \\
\hline
\end{tabular}

aM ismatch primers. The mismatch bases are in underlined italic. 
Table 3 Expected and observed numbers of CD G 1 patients with different genotypes. Frequencies, by counting, of $F 119 \mathrm{~L}$ and $\mathrm{R} 141 \mathrm{H}$ are $16 / 36=0.44$ and $16 / 36=0.44$, respectively

\begin{tabular}{lllc}
\hline G enotypes & $\begin{array}{l}\text { Expected } \\
\text { frequency }\end{array}$ & $\begin{array}{l}\text { Expected } \\
\text { number }\end{array}$ & $\begin{array}{l}\text { O bserved } \\
\text { number }\end{array}$ \\
\hline F 119L/F 119L & $(0.44)^{2}$ & 3.5 & 0 \\
F 119L/R 141H & $(2 \times 0.44 \times 0.44)$ & 7.0 & 15 \\
R 141H /R 141H & $(0.44)^{2}$ & 3.5 & 0 \\
O ther combinations & 0.26 & 4.0 & 3 \\
\hline
\end{tabular}

aF 119L/other, R 141H /other, and other/other.

$P=0.0009 ; \chi^{2}=16.4 ; d f=3$.

above markers and the additional marker D $1653020^{9,13}$ (Table 4). The mutation F119L was found with one specific haplotype in nine of 16 CDG 1 chromosomes. Since some of our patients were included in the investigation of Bjursell et $\mathrm{al}^{9}{ }^{9}$ we conclude that the $\mathrm{A}$ haplotype is associated with F119L. No specific haplotype was associated with the $\mathrm{R} 141 \mathrm{H}$ mutation when all four markers were included. When only D 165406 and D $16 S 3020$ were considered, seven of 16 R $141 \mathrm{H}$ chromosomes shared the same haplotype. We observed one recombination event between GATA-P6084, A FM a284wd5, D $16 S 406$ and (F 119L/D 16S3020) in one family. Two different D 16S3020 alleles were found to be in linkage disequilibrium with F119L (allele 11) and $\mathrm{R} 141 \mathrm{H}$ (allele 16), respectively.

\section{Discussion}

M ost patients with CDG 1 have a deficiency of phosphomannomutase, and intermediate activity of this enzyme is present in their parents. ${ }^{4,6}$ The locus for CDG 1 has been mapped to $16 p 13,{ }^{7,9}$ but the observation of families without evidence of this linkage suggests genetic heterogeneity. ${ }^{8}$ Two genes both encoding phosphomannomutase have been isolated, PM M 1 and PM M 2. ${ }^{10,11,13}$ PM M 1 maps to chromosome 22 and can therefore be excluded as a candidate gene for CDG 1. PMM 2 maps to 16p13, and mutations in this gene have been identified, strongly suggesting that PM M 2 is the gene responsible for CD G $1 .^{12,13}$

We investigated $18 \mathrm{D}$ anish families with a total of 22 children with CD 1 and identified 34 mutations on 36 disease chromosomes. Two mutations were found to account for $88 \%$ of the mutations. Sixteen of 36 CD G 1 alleles (44\%) harboured the F $119 \mathrm{~L}$ mutation and 16 of 36 CDG 1 alleles $(44 \%)$ the R $141 \mathrm{H}$ mutation. The activity of phosphomannomutase in 16 patients was low to undetectable. The very low activity of phospho- mannomutase in extracts of normal cultured fibroblasts made it difficult to compare the residual activities of mutant fibroblast extracts. ${ }^{4}$ Fifteen of 18 patients were compound heterozygous for $F 119 L / R 141 \mathrm{H}$, but only seven of these had detectable residual activity. It is not clear whether this is due to residual activity of the mutant enzyme or a contribution from the phosphomannomutase encoded by PMM $1 .^{16}$

Linkage analysis has previously suggested that a significant proportion of Scandinavian patients with CDG 1 have an ancestral mutation which segregates with a common haplotype A. ${ }^{9}$ We conclude from our results that this haplotype is associated with $\mathrm{F} 119 \mathrm{~L}$. The linkage disequilibrium between both of the common mutations, F $119 \mathrm{~L}$ and $\mathrm{R} 141 \mathrm{H}$, and two different alleles of D 16S3020 strongly suggests the presence of two ancestral mutations. $\mathrm{R} 141 \mathrm{H}$ was associated with a haplotype defined by only two markers D 165406 and D 1653020 (Table 2), suggesting that this mutation is older than F119L. The predominance of these mutations in Danish CD 1 patients emphasises the genetic homogeneity of the $D$ anish population known from previous studies of cystic fibrosis ${ }^{15}$ and galactosaemia (M. Salamon, personal communication 1997).

Our other findings include two new PMM 2 mutations, G 117R and D223E. The conservation of the involved amino acids in the highly homologous phosphomannomutases of man (PMM 1 and PMM 2), yeast (SE C 53), and Candida albicans ${ }^{10}$ suggests that these amino acids are crucial to the catalytic activity of the enzyme and that G 117R and D 223E are of pathogenic importance. In two of the patients, 1 and 9, only one mutation was found. The haplotypes defined by the markers A F M a284wd5, D 16 S406 and D $16 S 3020$ on the two chromosomes with an unknown mutation are identical and not found on any normal chromosome. We therefore expect these chromosomes to harbour identical mutations in PMM 2.

In view of the predominance of only two mutations we were surprised to find that no patient was homozygous for either one. The expected frequencies of homozygotes for both F119L and R $141 \mathrm{H}$ were 0.20 . This lack of homozygosity is highly significant $(P=0.0009)$ (Table 3). So far no patient has been reported to be homozygous for any mutation in PMM 2. ${ }^{12}$ However, two patients are known to be homozygous for the A haplotype, ${ }^{9}$ strongly suggesting homozygosity for F 119L. The most likely explanation is that the $\mathrm{R} 141 \mathrm{H}$ homozygous genotypes are lethal. If, on the other hand, homozygozity for $F 119 \mathrm{~L}$ results in a 
Table 4 Haplotypes found on 36 CD G 1 chromosomes and 36 normal chromosomes

\begin{tabular}{|c|c|c|c|c|c|c|c|c|c|}
\hline \multirow[b]{2}{*}{ M utation } & \multicolumn{4}{|c|}{ CD G 1 chromosomes } & \multirow[b]{2}{*}{$\begin{array}{l}\text { fam. } \\
\text { no }\end{array}$} & \multicolumn{4}{|c|}{ Normal chromosomes } \\
\hline & $\begin{array}{l}\text { GATA - } \\
\text { P6084 }\end{array}$ & $\begin{array}{l}\text { A FM a284 } \\
\text { wd5 }\end{array}$ & $\begin{array}{l}\text { D } 16 S \\
406\end{array}$ & $\begin{array}{l}\text { D 16S } \\
3020\end{array}$ & & $\begin{array}{l}\text { GATA - } \\
\text { P6084 }\end{array}$ & $\begin{array}{l}\text { A FM a284 } \\
\text { wd5 }\end{array}$ & $\begin{array}{l}\text { D 16S } \\
406\end{array}$ & $\begin{array}{l}\text { D 16S } \\
3020\end{array}$ \\
\hline \multirow{16}{*}{ F 119L } & 1 & 2 & 3 & 11 & 8 & 3 & 2 & 2 & 1 \\
\hline & 2 & 7 & 3 & 11 & 6 & 3 & 5 & 5 & 1 \\
\hline & 4 & 4 & 4 & 11 & 2 & 1 & 2 & 0 & 4 \\
\hline & 4 & 4 & 4 & 11 & 4 & 1 & 2 & 0 & 4 \\
\hline & 4 & 4 & 4 & 11 & 10 & 3 & 2 & 1 & 4 \\
\hline & 4 & 4 & 4 & 11 & 11 & 2 & 1 & 5 & 4 \\
\hline & 4 & 4 & 4 & 11 & 12 & 3 & 5 & 1 & 10 \\
\hline & 4 & 4 & 4 & 11 & 13 & 3 & 3 & 1 & 11 \\
\hline & 4 & 4 & 4 & 11 & 14 & 2 & 6 & 1 & 11 \\
\hline & 4 & 4 & 4 & 11 & 16 & 3 & 2 & 2 & 11 \\
\hline & 4 & 4 & 4 & 11 & 18 & 3 & 2 & 2 & 11 \\
\hline & 2 & 2 & 5 & 11 & 3 & 2 & 2 & 4 & 11 \\
\hline & 2 & 2 & 6 & 11 & 7 & 2 & 2 & 5 & 11 \\
\hline & 2 & 2 & 6 & 11 & 15 & 2 & 5 & 5 & 11 \\
\hline & 3 & 2 & 6 & 11 & 5 & 3 & 2 & 5 & 11 \\
\hline & n.i. & n.i. & n.i. & 11 & 17 & 4 & 2 & 5 & 11 \\
\hline \multirow[t]{16}{*}{ R 141H } & 3 & 2 & 1 & 16 & 9 & 1 & 2 & 7 & 11 \\
\hline & 1 & 2 & 3 & 16 & 16 & 16 & 2 & 7 & 11 \\
\hline & 2 & 2 & 3 & 16 & 4 & 4 & 2 & 9 & 11 \\
\hline & 2 & 2 & 3 & 16 & 6 & 6 & 2 & 5 & 12 \\
\hline & 2 & 2 & 3 & 16 & 11 & 11 & 3 & 4 & 13 \\
\hline & 2 & 1 & 3 & 16 & 13 & 13 & 2 & 5 & 13 \\
\hline & 3 & 2 & 3 & 16 & 3 & 3 & 5 & 1 & 14 \\
\hline & 4 & 0 & 3 & 16 & 14 & 14 & 2 & 4 & 14 \\
\hline & 2 & 2 & 4 & 16 & 10 & 10 & 1 & 5 & 14 \\
\hline & 2 & 6 & 4 & 16 & 15 & 15 & 2 & 5 & 14 \\
\hline & 1 & 2 & 5 & 16 & 2 & 2 & 2 & 2 & 15 \\
\hline & 1 & 2 & 5 & 16 & 5 & 5 & 2 & 2 & 15 \\
\hline & 2 & 2 & 5 & 16 & 18 & 18 & 2 & 5 & 15 \\
\hline & 3 & 2 & 6 & 16 & 7 & 7 & 1 & 5 & 15 \\
\hline & 3 & 2 & 6 & 16 & 12 & 12 & 5 & 1 & 16 \\
\hline & n.i. & n.i. & n.i. & 16 & 17 & 17 & 2 & 5 & 16 \\
\hline G 117R & 2 & 2 & 6 & 11 & 8 & 9 & 2 & 5 & 16 \\
\hline D 223E & 2 & 3 & 4 & 15 & 1 & 1 & 2 & 6 & 16 \\
\hline \multirow{2}{*}{ Unknown } & 2 & 2 & 4 & 12 & 1 & 4 & 2 & 8 & 16 \\
\hline & 3 & 2 & 4 & 12 & 9 & 3 & 2 & 6 & 17 \\
\hline
\end{tabular}

G ATA -P6084: allele 1=109 bp; A F M a284wd5: allele 1=238 bp; D 16S406: allele 1=180 bp; 16S3020: allele 1=62 bp.

n.i.: parents not informative.

$\mathrm{N}$ umbers in bold represent the alleles in linkage disequilibrium with $\mathrm{F} 119 \mathrm{~L}$ and R $141 \mathrm{H}$, respectively.

very mild phenotype, such patients could be underdiagnosed. This would also explain why compound heterozygosity would convey a phenotype compatible with survival, albeit with substantial morbidity.

The phosphomannomutase encoded for by yeast SE C 53 is a dimeric protein. ${ }^{16,17}$ If the product of PM M 2 in man has a similar structure, interallelic complementation could rescue a genotype with one lethal and one mild mutation.

The role of the PMM 1 enzyme in mannose metabolism is still puzzling. The two PMM genes are highly homologous, catalyse the same reaction and are apparently expressed in the same tissues. ${ }^{10,12}$ A II PMM 2 patients express no or very low phosphomannomutase in leucocytes, although PMM 1 mRNA is found in normal levels in these cells. ${ }^{10} \mathrm{~A}$ possible explanation could be that the activity of PMM 1 is dependent on PM M 2 phosphomannomutase. Future in vitro expression studies may clarify the phenotypic consequences of mutations in PMM 2.

\section{Acknowledgements}

We are grateful to D rs G ert M atthijs and E Is Schollen, Center for Human Genetics, U niversity of Leuven, Belgium, for information about the oligonucleotide primers used for PCR and SSCP analyses of PMM 2 and for information about the closely linked marker D 16S3020. We thank the Novo N ordic 
Foundation, B irthe and E rik M eyer's Fond, Gerda and $A$ age $\mathrm{H}$ aensch's Fond, and Dagmar M arshall's Fond for financial support. The excellent technical assistance from Bodil Mogensen and Pernille Ledertoug Larsen is greatly appreciated. We also acknowledge the contributions by the patients and their families.

\section{References}

1 Jaeken J, Stibler H, H agberg B (eds): The carbohydratedeficient glycoprotein syndrome. A new inherited multisystemic disease with severe nervous system involvement. A cta Paediatr Scand 1991; 375 (suppl.): 1-71.

$2 \mathrm{H}$ agberg BA, Blennow $\mathrm{G}, \mathrm{K}$ ristiansson $\mathrm{B}$, Stibler $\mathrm{H}$ : Carbohydrate-deficient glycoprotein syndromes: peculiar group of new disorders. Pediatr N eurol 1993; 9: 255-262.

3 Stibler $\mathrm{H}$, Jaeken J, Kristiansson B: B iochemical characteristics and diagnosis of the carbohydrate-deficient glycoprotein syndrome. A cta Paediatr Scand 1991; 375 (suppl): 21-31.

4 Van Schaftingen E, Jaeken J: Phosphomannomutase deficiency is a cause of carbohydrate-deficient glycoprotien syndrome type I. FE BS L ett 1995; 377: 318-320.

5 Jaeken J, M atthijs G, B arone R, Carchon $\mathrm{H}$ : Syndrome of the month: carbohydrate-deficient glycoprotein (CDG) syndrome type I. J M ed G enet 1997; 34: 73-77.

6 Jaeken J, A rtigas J, B arone $\mathrm{R}$ et al: Phosphomannomutase deficiency is the main cause of carbohydrate-deficient glycoprotein syndrome with type I isoelectrofocusing pattern of serum sialotransferrins. J I nher M etab Dis 1997; 20: 447-449.

$7 \mathrm{M}$ artinsson T, B jursell $\mathrm{C}$, Stibler $\mathrm{H}$ et al: $\mathrm{L}$ inkage of a locus for carbohydrate-deficient glycoprotein syndrome type I (CD G 1) to chromosome $16 \mathrm{p}$, and linkage disequilibrium to microsatellite marker D 16S406. H um M ol G enet 1994; 3: 2037-2042.

8 Matthijs G, Legius E, Schollen E et al: Evidence for genetic heterogeneity in the carbohydrate-deficient glycoprotein syndrome type I (CDG1). Genomics 1996; 35: 597-599.
9 Bjursell C, Stibler H, Wahlström J et al: Fine mapping of the gene for carbohydrate-deficient glycoprotein syndrome type I (CD G 1): linkage disequilibrium and founder effect in Scandinavian families. Genomics 1997; 39: 247-253.

10 Matthijs G, Schollen E, Pirard M, Budarf $M L$, Van Schaftingen E, Cassiman J J: PMM (PMM 1), the human homologue of SEC53 or yeast phosphomannomutase, is localized on chromosome 22q13. Genomics 1997; 40: 41-47.

11 Wada $Y$, Sakamoto $M$ : I solation of the human phosphomannomutase gene (PMM 1) and assignment to chromosome 22q13. G enomics 1997; 39: 416-417.

12 Matthijs G, Schollen E, Pardon $E$ et al: Mutations in PMM 2, a phosphomannomutase gene on chromosome $16 \mathrm{p} 13$, in carbohydrate-deficient glycoprotein type I syndrome. N at G enet 1997; 16: 88-92.

13 Schollen E, Pardon E, Heykants L et al: Comparative analysis of the phosphomannomutase genes PMM 1 , PMM 2 and PMM $2 \psi$ : the sequence variation in the processed pseudogene is a reflection of the mutations found in the functional gene. Hum Mol Genet 1998; 7: 157-164.

14 Matthijs G, Schollen E, Van Schaftingen E, Cassiman J -J, Jaeken J: Lack of homozygotes for the most frequent disease allele in carbohydrate-deficient glycoprotein syndrome type IA (Jaeken syndrome). A m J H um G enet. In press.

15 Schwartz M, Brandt NJ, Skovby F : Screening for carriers of cystic fibrosis among pregnant women: A pilot study. E ur J H um G enet 1993; 1: 239-244.

16 Pirard $M$, Collet J-F, M atthijs G, Van Schaftingen E: Comparison of PMM 1 with the phosphomannomutases expressed in rat liver and in human cells. FE BS L ett 1997; 411: 251-254.

17 Kepes F, Schekman R: The yeast SEC 53 gene encodes phosphomannomutase. J Biol Chem 1988; 263: 9155-9161. 